Check for updates

Cite this: RSC Adv., 2018, 8, 3077

Received 15th July 2018

Accepted 9th August 2018

DOI: $10.1039 / \mathrm{c} 8 \mathrm{ra06020 \textrm {g }}$

rsc.li/rsc-advances

\section{A nano-micro dual-scale particulate-reinforced copper matrix composite with high strength, high electrical conductivity and superior wear resistance}

\author{
Cunlei Zou, $\uparrow^{a}$ Zongning Chen, $\uparrow^{a}$ Enyu Guo, $\uparrow^{a}$ Huijun Kang,$\dagger^{\star a}$ Guohua Fan,$\dagger^{b}$ \\ Wei Wang, $\dagger^{a}$ Rengeng $\mathrm{Li}_{\mathrm{i}} \dagger^{\mathrm{a}}$ Siruo Zhang $\dagger^{\mathrm{a}}$ and Tongmin Wang $\left(\mathbb{D} \dagger^{\star a}\right.$
}

Due to the contradiction between mechanical properties and electrical conductivity, it is not easy to fabricate materials with both high strength and good wear resistance with favourable electrical conductivity for the application of electrical materials. In addition, strength and wear resistance do not always present a uniform growth trend at the same time. Herein, a novel copper matrix composite reinforced by in situ synthesized $\mathrm{ZrB}_{2}$ microparticles and nano $\mathrm{Cu}_{5} \mathrm{Zr}$ precipitates is successfully prepared by a casting method and sequential heat treatments. The $\mathrm{Cu} /$ dual-scale particulate composite possesses a desired trade-off of strength, electrical conductivity and wear resistance. $\mathrm{ZrB}_{2}$ microparticles form from $\mathrm{Zr}$ and $\mathrm{B}$ elements in copper melts, and nanoscale $\mathrm{Cu}_{5} \mathrm{Zr}$ precipitates form in the matrix after solid solution and aging treatments. The $\mathrm{ZrB}_{2}$ microparticles, nano $\mathrm{Cu}_{5} \mathrm{Zr}$ precipitates, and well-bonded interfaces contribute to a high tensile strength of $591 \mathrm{MPa}$ and superior wear resistance, with a relative electrical conductivity of $83.7 \%$ International Annealed Copper Standard.

\section{Introduction}

Owing to the high thermal/electrical conductivity and good mechanical properties, copper matrix composites (CMCs) have been developed for decades. And CMCs are promising for the applications of electrical contact, rail transit contact wires, electrode of spot welding and so on. ${ }^{\mathbf{1 - 5}}$ However, as always there is a trade-off among mechanical properties, electrical properties and wear properties. ${ }^{6,7}$ Especially in copper alloys, due to the severe lattice distortion leading to solid solution atoms, high strength is usually obtained at the great expense of electrical conductivity. ${ }^{8,9}$ However, in CMCs, there are few or no solid solution atoms in the copper matrix, and the presence of thermodynamically stable ceramic particulates dispersed in a copper matrix can greatly enhance the mechanical properties of copper without sacrificing its electrical conductivity notably. ${ }^{\mathbf{1 0 - 1 2}}$ The conventional ingot metallurgy approach offers unique benefits due to the low production cost, and in recent decades, efforts have been devoted to improving the mechanical performance of ceramic particulate-reinforced copper matrix composites (CMCs) fabricated by casting routes. ${ }^{13-15}$ However, it

\footnotetext{
${ }^{a}$ Key Laboratory of Solidification Control and Digital Preparation Technology (Liaoning Province), School of Material Science and Engineering, Dalian University of Technology, Dalian 116024, China. E-mail: kanghuijun@dlut.edu.cn; tmwang@ dlut.edu.cn

${ }^{b}$ School of Materials Science and Engineering, Harbin Institute of Technology, Harbin 150001, China

$\dagger$ These authors contributed equally to this work.
}

is challenging to simultaneously optimize two of the most imperative properties of CMCs - the strength and tribological properties-because the former requires the particulate phase to be small enough $(<500 \mathrm{~nm})$ to take advantage of Orowan strengthening, while the latter prefers dispersed particles of a larger size $(>1 \mu \mathrm{m})$, such that the composites can be load bearing and not merely act as obstacles to the movement of dislocations. ${ }^{16-19}$ The CMCs fabricated by casting routes usually consist of large reinforced particles, and the dispersionstrengthened copper alloys obtained by heat treatment always consist of many reinforcing nanoparticles. ${ }^{\mathbf{2 0 , 2 1}}$ Therefore, the CMCs fabricated by in situ casting and heat treatment will consist of dual-scale particles and will possess both good mechanical properties and wear resistance. As yet, there are few reports that document castable CMCs that simultaneously possess high strength, high electrical conductivity, and superior wear resistance.

Herein, we developed $\mathrm{Cu}-\mathrm{Zr}-\mathrm{ZrB}_{2}$ composites that combine high strength, high electrical conductivity, and superior wear resistance. The composites were fabricated by in situ melt reactions, followed by casting and heat treatment. $\mathrm{ZrB}_{2}$ microparticles were in situ formed in a copper melt, and Zr-rich nanoparticles precipitated upon the subsequent heat treatment. The $\mathrm{Cu}-\mathrm{Zr}-\mathrm{ZrB}_{2}$ system was selected based on the following design considerations: (i) $\mathrm{Cu}-\mathrm{Zr}$ alloys have high electrical conductivity due to the negligible solid solubility of $\mathrm{Zr}$ in $\mathrm{Cu}$ at room temperature; ${ }^{22}$ (ii) upon aging, nanoscale $\mathrm{Zr}$ containing precipitates will significantly improve the strength of the composite; ${ }^{\mathbf{8} 23}$ (iii) the in situ formed $\mathrm{ZrB}_{2}$ particles are 
stable and microsized, which is conducive to increasing the wear resistance of the composite, ${ }^{\mathbf{2 4 , 2 5}}$ as well-demonstrated in many particulate-reinforced aluminum matrix composites. ${ }^{26,27}$ It is expected that the $\mathrm{Cu}-\mathrm{Zr}-\mathrm{ZrB}_{2}$ composites thus produced will exhibit high strength, high conductivity, and superior wear resistance.

\section{Experimental procedure}

The raw materials were $\mathrm{Cu}$ (99.97\% purity), and $\mathrm{Cu}-5 \mathrm{~B}, \mathrm{Cu}-10 \mathrm{Zr}$ master alloys. The master alloys were pre-prepared in highfrequency furnace. The $\mathrm{Cu}-\mathrm{Zr}-\mathrm{ZrB}_{2}$ composites were in situ fabricated in a vacuum induction furnace. When $\mathrm{Cu}$ melted in the graphite crucible, $\mathrm{Cu}-\mathrm{B}$ and $\mathrm{Cu}-\mathrm{Zr}$ were sequentially incorporated into the melt. After holding for $5 \mathrm{~min}$, the melt was poured into a cylindrical graphite mold $45 \mathrm{~mm}$ in diameter and $220 \mathrm{~mm}$ in height. The as-cast billets were homogeneously annealed at $960{ }^{\circ} \mathrm{C}$ for $3 \mathrm{~h}$ and hot rolled at $850{ }^{\circ} \mathrm{C}$ for a $17 \%$ reduction (from the thickness of 30 to $25 \mathrm{~mm}$ ). The samples were then solution treated at $960{ }^{\circ} \mathrm{C}$ for $1 \mathrm{~h}$ and removed the oxide layer to $23 \mathrm{~mm}$ thickness. Subsequently, the samples were further rolled at room temperature about $20^{\circ} \mathrm{C}$ from 23 to $2 \mathrm{~mm}$ for a $91 \%$ reduction and aged in a vacuum furnace at $400{ }^{\circ} \mathrm{C}$ for 30, 60, 90, 120, and $150 \mathrm{~min}$. Cu-0.3 wt\% Zr with 0, 0.5\%, 1\%, and $2.0 \%$ weight percent $\mathrm{ZrB}_{2}$ were prepared for test.

For the microstructure investigation, the samples were etched with a corrosive agent consisting of $3 \mathrm{~g} \mathrm{FeCl}_{3}, 2 \mathrm{~mL} \mathrm{HCl}$, and $95 \mathrm{~mL} \mathrm{C}_{2} \mathrm{H}_{5} \mathrm{OH}$. Phases in the composites were identified using an EMPYREAN X-ray diffractometer (XRD) with $\mathrm{Cu} \mathrm{K} \alpha$ radiation scanning from $20^{\circ}$ to $100^{\circ}$ in $2 \theta$ at a scanning speed of $0.26738^{\circ} \mathrm{s}^{-1}$. A Zeiss Supra 55 scanning electron microscope (SEM) operated in the secondary electron mode with an accelerating voltage of $15 \mathrm{kV}$ was used to observe the microstructure of the $\mathrm{Cu}-\mathrm{Zr}-\mathrm{ZrB}_{2}$ composites. The transmission electron microscopy (TEM) images were obtained by a Talos F200X field emission transmission electron microscope at an accelerating voltage of $200 \mathrm{kV}$. The tensile specimens were machined from the samples according to the ASTM-E8 standard. Tensile tests were carried out at room temperature with a crosshead speed of $2 \mathrm{~mm} \mathrm{~min}^{-1}$. The dry sliding specimens were prepared from $5.0 \mathrm{~mm}$ rolled samples according to the ASTM G99-05. The dry sliding wear tests were performed using a pin-on-disk apparatus (MVF-1A multifunctional friction and wear tester) at room temperature. These samples were machined into pins, and the discs were made with conventional $45 \#$ steel with a hardness of $465 \mathrm{HV}$. The volume wear loss of the samples was calculated by measuring the wear scar in the SEM images.

\section{Results and discussion}

We prepared four $\mathrm{Cu}-\mathrm{Zr}-\left(\mathrm{ZrB}_{2}\right)$ composites with nominal $\mathrm{ZrB}_{2}$ mass fractions of $0,0.5,1.0$, and 2.0. The XRD patterns of the $\mathrm{Cu}-\mathrm{Zr}-\mathrm{ZrB}_{2}$ composites are shown in Fig. 1(a). Only two types of signals, which correspond to $\mathrm{Cu}$ and $\mathrm{ZrB}_{2}$ reflections, can be
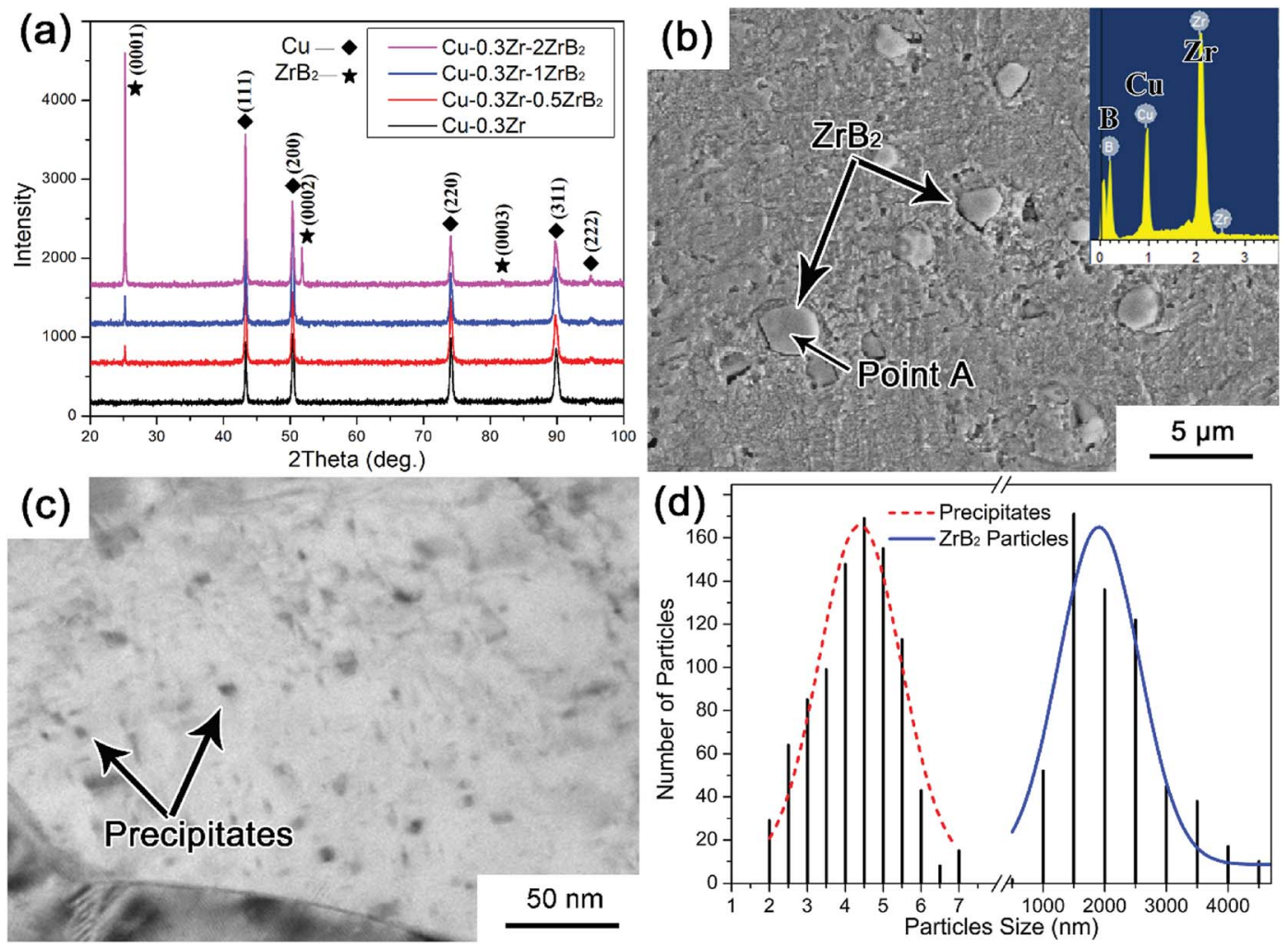

Fig. 1 Characterization results of the composites: (a) XRD patterns of $\mathrm{Cu}-\mathrm{Zr}-\left(\mathrm{ZrB} \mathrm{B}_{2}\right)$, (b) SEM and EDS images of the $\mathrm{Cu}-0.3 \mathrm{wt} \% \mathrm{Zr}-1 \mathrm{wt} \% \mathrm{ZrB} 2$ composite: $A$ is the point scanning of the corresponding area in the SEM image, (c) TEM image of the precipitate phase, (d) size distribution of the dual-scale reinforcing particles. 
distinguished in the XRD spectra. The $\mathrm{ZrB}_{2}$ peaks become increasingly evident with increasing $\mathrm{ZrB}_{2}$ content, indicating that $\mathrm{ZrB}_{2}$ reinforcement can be quantitatively controlled by the in situ casting method. The SEM image in Fig. 1(b) shows that the $\mathrm{ZrB}_{2}$ particles are microsized and homogeneously distributed in the matrix. The EDS pattern provided in the inset of Fig. 1(b) also confirms the formation of $\mathrm{ZrB}_{2}$. Fig. 1(c) shows the TEM image of the $\mathrm{Cu}-0.3 \mathrm{Zr}-1 \mathrm{ZrB}_{2}$ composite, and many nanoparticles are detected throughout the matrix. Fig. 1(d) presents the size distribution of the $\mathrm{ZrB}_{2}$ particles and precipitates statistically measured from the SEM and TEM images. It can be seen that the particles ( $\mathrm{ZrB}_{2}$ and precipitates) have a bimodal size distribution with a mean $\mathrm{ZrB}_{2}$ particle size of $\sim 2$ $\mu \mathrm{m}$ and mean precipitate particle size of $\sim 5 \mathrm{~nm}$.

The TEM results of the $\mathrm{Cu}-\mathrm{Zr}-\mathrm{ZrB}_{2}$ composites are shown in Fig. 2. Fig. 2(a) shows the typical bright-field TEM images of the microparticle/Cu pairs in the composite. The selected area electron diffraction (SAED) patterns of the particle correspond to $\mathrm{ZrB}_{2}$. The $\mathrm{ZrB}_{2}$ particle is blocky and has straight boundaries with the copper matrix. Fig. 2(b) is a high-resolution TEM image showing the $\mathrm{ZrB}_{2}-\mathrm{Cu}$ interface, which is clean and reveals no undesirable reaction products. However, a transition layer with relatively high strain is noted at the interface, which is ascribed to the high lattice mismatch between $\mathrm{ZrB}_{2}$ and $\mathrm{Cu}$. The disregistry between $\mathrm{Cu}$ and $\mathrm{ZrB}_{2}$ is calculated according to $\delta=$ $2\left(a_{\mathrm{ZrB}_{2}}-a_{\mathrm{Cu}}\right) /\left(a_{\mathrm{ZrB}_{2}}+a_{\mathrm{Cu}}\right)$ to be $13.16 \%$ based on their lattice parameters. The tight interfacial bonding is a prerequisite to attain superior mechanical properties that are conducive to improving the tribological performance of the composite.

The higher-magnified bright-field TEM image (Fig. 2(c)) shows the nanoparticles distributed inside the $\mathrm{Cu}$ grains. These particles, which were precipitated from the supersaturated $\mathrm{Cu}-$ $\mathrm{Zr}$ solid solution upon aging, are indexed as $\mathrm{Cu}_{5} \mathrm{Zr}$ by SAED analysis in the inset of Fig. 2(c). According to the SAED in Fig. 2(c), the zone axes of both $\mathrm{Cu}_{5} \mathrm{Zr}$ and the $\mathrm{Cu}$ matrix are [111], and the orientation relationship between the two is determined to be $(20 \overline{2})_{\mathrm{Cu}_{5} \mathrm{r}} / /(20 \overline{2})_{\mathrm{Cu}}$ and $[111]_{\mathrm{Cu}} / /[111]_{\mathrm{Cu}_{5} \mathrm{zr}}$. This is further evidenced by the high-resolution TEM analysis in Fig. 2(d). The corresponding SAED of [112] zone axis also confirm the $\mathrm{Cu}_{5} \mathrm{Zr}$ precipitate and the orientation relationship. These nanosized $\mathrm{Cu}_{5} \mathrm{Zr}$ precipitates are believed to be responsible for improving the tensile properties of the composites.

The variations of the electrical conductivity of the assolution-annealed and as-aged $\mathrm{Cu}-\mathrm{Zr}-\left(\mathrm{ZrB}_{2}\right)$ composites as a function of $\mathrm{ZrB}_{2}$ content are shown in Fig. 3(a). After aging, the electrical conductivity increases significantly, from about 55$60 \%$ International Annealed Copper Standard (IACS) to $78-86 \%$ IACS for the as-solution-annealed and as-aged samples,
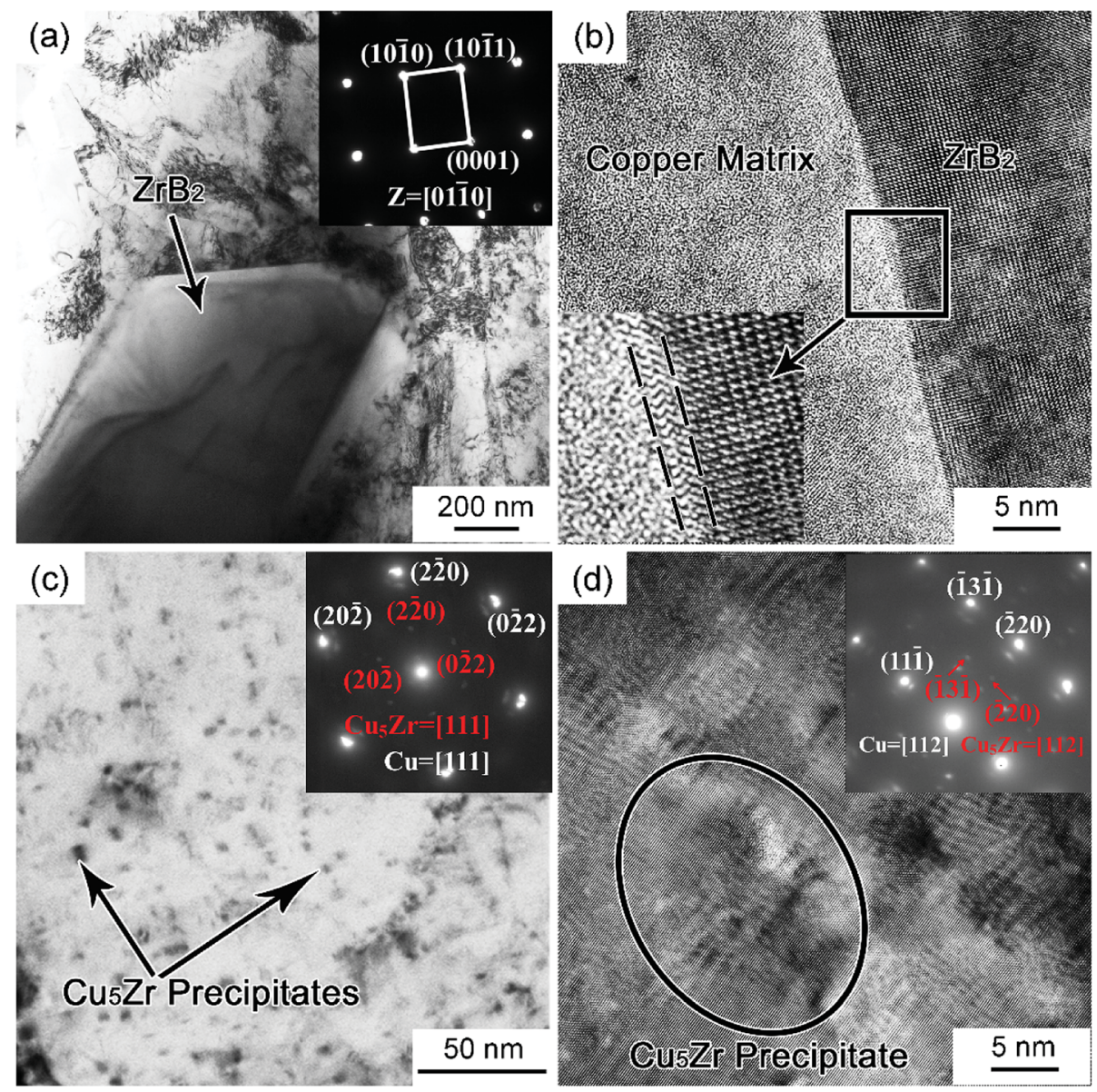

Fig. 2 TEM images of the $\mathrm{Cu}-0.3 \mathrm{wt} \% \mathrm{Zr}-1 \mathrm{wt} \% \mathrm{ZrB}_{2}$ composite: (a) ZrB 2 particle and copper matrix, (b) interface between $\mathrm{ZrB}{ }_{2}$ and copper, (c) bright-field image and SAED of the precipitates in the copper matrix, (d) high-resolution TEM image of the $\mathrm{Cu}_{5} \mathrm{Zr}$ precipitates. 
(a)

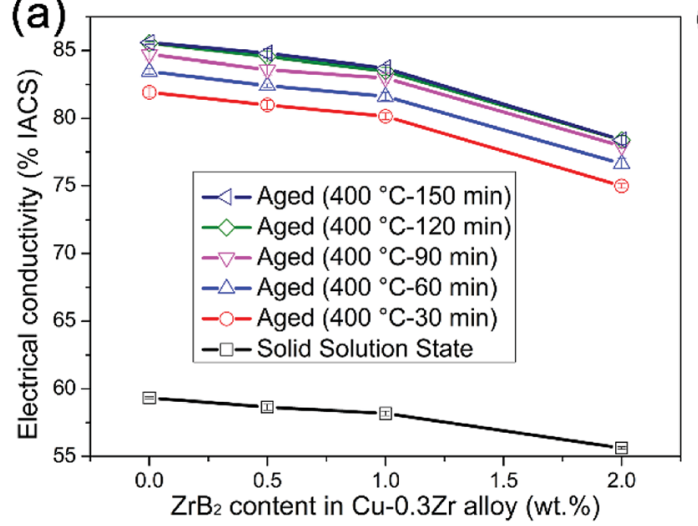

(b)

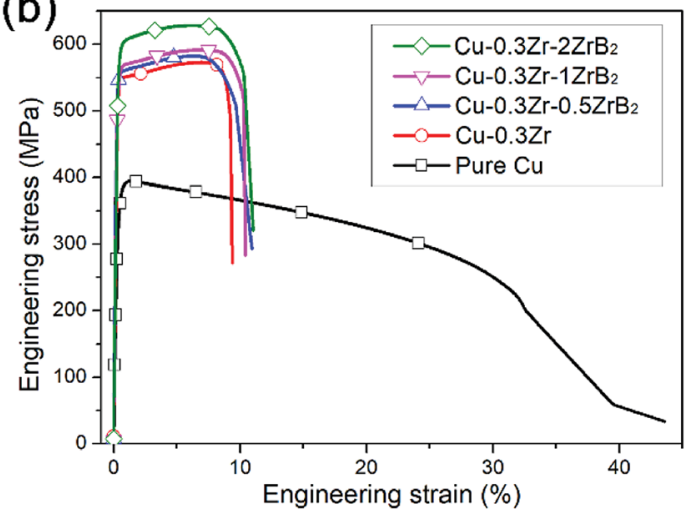

Fig. 3 Electrical conductivity and tensile strength of $\mathrm{Cu}-\mathrm{Zr}-\left(\mathrm{ZrB}_{2}\right)$ composites: (a) electrical conductivity and (b) stress-strain curves.

respectively, depending on the $\mathrm{ZrB}_{2}$ level. When the aging time increases from $30 \mathrm{~min}$ to $120 \mathrm{~min}$ at $400{ }^{\circ} \mathrm{C}$, the electrical conductivity increases slightly and does not visibly improve when the aging time increases from $120 \mathrm{~min}$ to $150 \mathrm{~min}$, which indicates that sufficient precipitation has occurred in the composites during a $120 \mathrm{~min}$ aging process. The electrical conductivity of $\mathrm{Cu}-\mathrm{Zr}-\mathrm{ZrB}_{2}$ slightly decreases from about $85 \%$ IACS to $78 \%$ IACS with an increase in $\mathrm{ZrB}_{2}$ content. Matthiessen's rule can be expressed as $\rho=\rho(T)+\rho_{\mathrm{i}}$, where $\rho$ is the total resistivity of the metals, $\rho(T)$ is the resistivity of the metal, which varies with temperature, and $\rho_{\mathrm{i}}$ is the resistivity induced by chemical and physical defects including impurity atoms, interstitial defects, dislocations, and so on. ${ }^{28,29}$ The crystal lattice distortion caused by solid solution $\mathrm{Zr}$ atoms will scatter electrons intensively and significantly decrease the electrical conductivity. Therefore, separating $\mathrm{Cu}_{5} \mathrm{Zr}$ from the copper matrix could reduce the number of solid solution $\mathrm{Zr}$ atoms, leading to a considerable increase in the electrical conductivity.

The stress-strain curves of the $\mathrm{Cu}-0.3 \mathrm{Zr}-x \mathrm{ZrB}_{2}$ composites are compared with those of pure copper and of the $\mathrm{Cu}-0.3 \mathrm{Zr}$ alloy, as shown in Fig. 3(b). One can see that, compared with pure copper, the tensile tests only record marginal differences in the yield strength and ultimate tensile strength (UTS) between the samples with various $\mathrm{ZrB}_{2}$ contents, indicating that
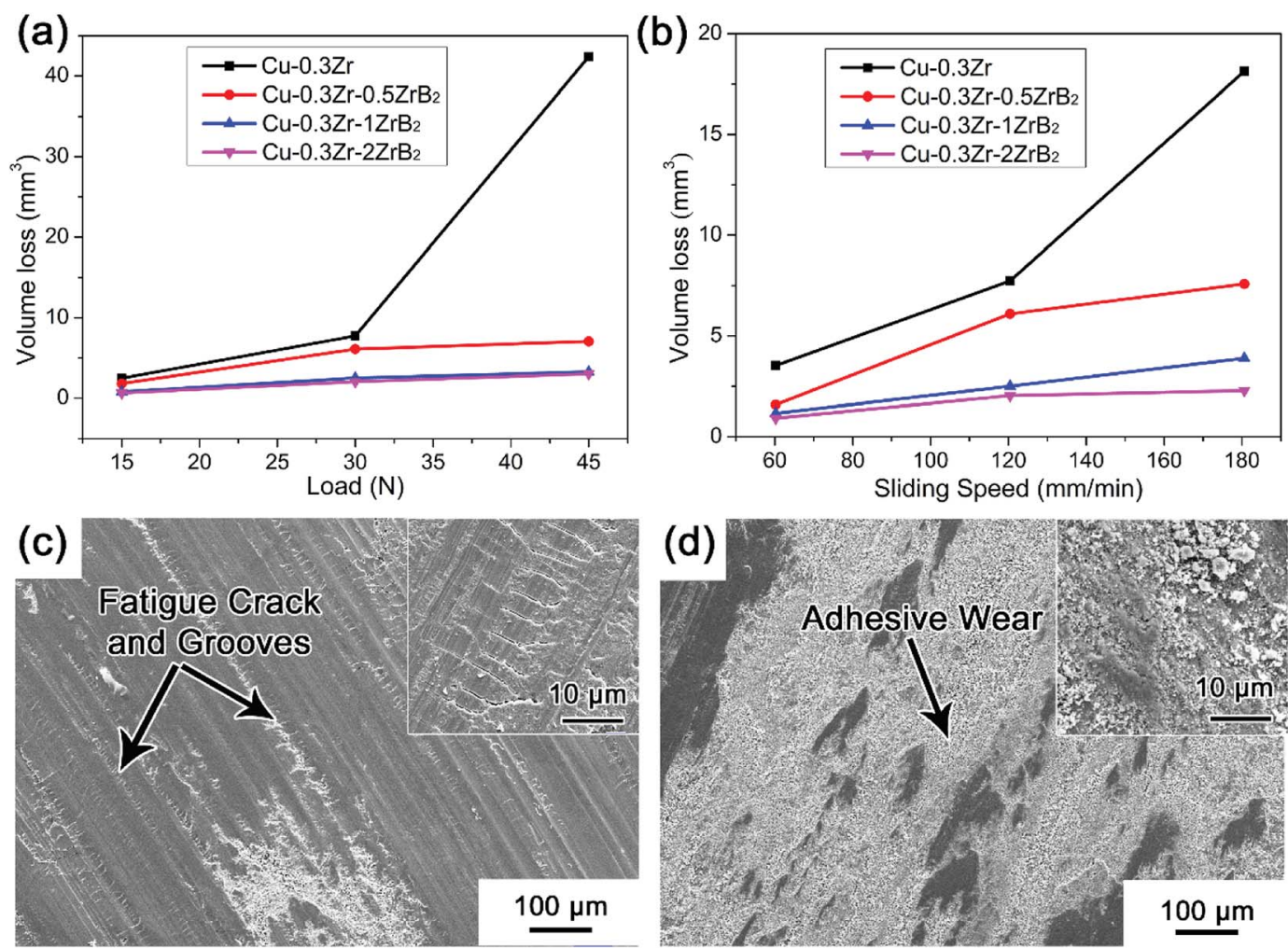

Fig. 4 Volume wear loss of $\mathrm{Cu}-\mathrm{Zr}-\left(\mathrm{ZrB}_{2}\right)$ composites: (a) different loads and (b) different sliding speeds. Wear scar of (c): $\mathrm{Cu}-0.3$ wt\% $\mathrm{Zr}$ and (d) $\mathrm{Cu}-0.3 \mathrm{wt} \% \mathrm{Zr}-1 \mathrm{wt} \% \mathrm{ZrB}_{2}$. 
the large $\mathrm{ZrB}_{2}$ particles contribute little to the strength of the composite. This is probably because the strengthening of the $\mathrm{Cu}-0.3 \mathrm{Zr}-x \mathrm{ZrB}_{2}$ composites is dominated by the Orowan mechanism, as can be calculated by the following equation: ${ }^{30}$

$$
\Delta \sigma_{\text {Orowan }}=0.13 G b \ln (r / b) / \lambda,
$$

where $G$ is the shear modulus $(38.4 \mathrm{GPa}), b$ is Burger's vector $\left(2^{1 /}\right.$ $\left.{ }^{2} a_{\mathrm{Cu}}=0.2556 \mathrm{~nm}\right), r$ is the mean particle radius $\left(r_{\mathrm{Cu}_{5} \mathrm{Zr}}=\right.$ $4.16 \mathrm{~nm}$ and $\left.r_{\mathrm{ZrB}_{2}}=1970 \mathrm{~nm}\right) ; \lambda$ is the interparticle spacing (calculated by $\lambda=2 r\left[\left(1 / 2 f_{\mathrm{v}}\right)^{1 / 3}-1\right]$, where $f_{\mathrm{v}}$ is the volume fraction $\left.^{31}\right)$. According to the parameters obtained from the literature and in this study, the Orowan strengthening contribution of $\mathrm{Cu}_{5} \mathrm{Zr}$ is calculated to be $277 \mathrm{MPa}$, and that of $\mathrm{ZrB}_{2}$ is only 2.32 $\mathrm{MPa}$. Therefore, materials with nanosized $\mathrm{Cu}_{5} \mathrm{Zr}$ precipitates present a high tensile strength, while microsize $\mathrm{ZrB}_{2}$ particles cause only a slight improvement in the tensile strength.

The effect of different loads and sliding speeds on the volume wear loss of the $\mathrm{Cu}-\mathrm{Zr}-\left(\mathrm{ZrB}_{2}\right)$ pin samples are summarized in Fig. 4(a) and (b). Compared with $\mathrm{Cu}-\mathrm{Zr}-\mathrm{ZrB}_{2}$, a higher volume wear loss can be observed for the $\mathrm{Cu}-0.3 \mathrm{Zr}$ alloy without incorporation of $\mathrm{ZrB}_{2}$, especially at higher load (45 N) and sliding speed $(150 \mathrm{rpm})$. This evidence confirms the effectiveness of the in situ formed $\mathrm{ZrB}_{2}$ particles in improving the wear resistance of copper alloys. The wear scar features of the $\mathrm{Cu}-$ $0.3 \mathrm{Zr}$ alloy and $\mathrm{Cu}-0.3 \mathrm{Zr}-1 \mathrm{ZrB}_{2}$ composite are presented in Fig. 4(c) and (d), respectively. For the $\mathrm{Cu}-\mathrm{Zr}$ alloy, fatigue cracks are found to be perpendicular to the scratch (high resolution at the right high corner). A mass of wear debris can be seen at the end of grooves, indicating that the debris plow grooves in the contact surfaces, where severe wear loss occurs. Unlike the $\mathrm{Cu}-$ $\mathrm{Zr}$ alloy, the sliding surface of $\mathrm{Cu}-0.3 \mathrm{Zr}-1 \mathrm{ZrB}_{2}$ features adhesive wear and fewer grooves, indicating that the $\mathrm{ZrB}_{2}$ particles resist the occurrence of fatigue crack. Therefore, the $\mathrm{Cu}-\mathrm{Zr}-\mathrm{ZrB}_{2}$ composites exhibit superior wear resistance.

\section{Conclusions}

In conclusion, we developed a dual-scale particulate-reinforced $\mathrm{Cu}-\mathrm{Zr}-\mathrm{ZrB}_{2}$ composite with $\mathrm{ZrB}_{2}$ microparticles and $\mathrm{Cu}_{5} \mathrm{Zr}$ precipitate nanoparticles fabricated by an ingot metallurgy route with a low cost. The $\mathrm{ZrB}_{2}$ microparticles contribute to the wear resistance, while the $\mathrm{Cu}_{5} \mathrm{Zr}$ precipitate nanoparticles enhance the strength by Orowan strengthening. In the laboratory, we obtained a combined UTS of $591 \mathrm{MPa}$, good wear resistance, and an acceptable electrical conductivity of $83.7 \%$ IACS for the $\mathrm{Cu}-0.3 \mathrm{wt} \% \mathrm{Zr}-1 \mathrm{wt} \% \mathrm{ZrB}_{2}$ composite.

\section{Conflicts of interest}

There are no conflicts to declare.

\section{Acknowledgements}

The authors gratefully acknowledge the support of the National Key Research and Development Program of China (No.
2017YFA0403804), the National Natural Science Foundation of China (No. 51525401, 51601028, 51774065, 51690163) and Dalian Support Plan for Innovation of High-level Talents (Top and Leading Talents, 2015R013).

\section{Notes and references}

1 X. Zhang, C. Shi, E. Liu, F. He, L. Ma, Q. Li, J. Li, W. Bacsa, N. Zhao and C. He, Nanoscale, 2017, 9, 11929-11938.

2 A. Mortensen and J. Llorca, Annu. Rev. Mater. Res., 2010, 40, 243-270.

3 I. Firkowska, A. Boden, B. Boerner and S. Reich, Nano Lett., 2015, 15, 4745-4751.

4 C. N. He, N. Q. Zhao, C. S. Shi, E. Z. Liu and J. J. Li, $A d v$. Mater., 2015, 27, 5422-5431.

5 K. Bi, Q. Xiang, Y. Chen, H. Shi, Z. Li, J. Lin, Y. Zhang, Q. Wan, G. Zhang, S. Qin, X. Zhang and H. Duan, Nanoscale, 2017, 9, 16755-16763.

6 S. C. Tjong and Z. Y. Ma, Mater. Sci. Eng., R, 2000, 29, 49-113. 7 L. Lu, Y. Shen, X. Chen, L. Qian and K. Lu, Science, 2004, 304, 422.

8 R. Li, H. Kang, Z. Chen, G. Fan, C. Zou, W. Wang, S. Zhang, Y. Lu, J. Jie, Z. Cao, T. Li and T. Wang, Sci. Rep., 2016, 6, 20799.

9 W. Wang, H. Kang, Z. Chen, Z. Chen, C. Zou, R. Li, G. Yin and T. Wang, Mater. Sci. Eng., A, 2016, 673, 378-390.

10 J. Zhang, L. He and Y. Zhou, Scr. Mater., 2009, 60, 976-979. 11 Y. Zhan and G. Zhang, Mater. Lett., 2003, 57, 4583-4591.

12 J. P. Tu, N. Y. Wang, Y. Z. Yang, W. X. Qi, F. Liu, X. B. Zhang, H. M. Lu and M. S. Liu, Mater. Lett., 2002, 52, 448-452.

13 J. W. Kaczmar, K. Pietrzak and W. Wlosinski, J. Mater. Process. Technol., 2000, 106, 58-67.

14 X. Wang, H. Ding, F. Qi, Q. Liu, X. Fan and Y. Shi, J. Alloys Compd., 2017, 695, 3410-3418.

15 R. Aparicio-Fernández, H. Springer, A. Szczepaniak, H. Zhang and D. Raabe, Acta Mater., 2016, 107, 38-48.

16 C. Zou, H. Kang, W. Wang, Z. Chen, R. Li, X. Gao, T. Li and T. Wang, J. Alloys Compd., 2016, 687, 312-319.

17 D. Deschuyteneer, F. Petit, M. Gonon and F. Cambier, Surf. Coat. Technol., 2017, 311, 365-373.

18 C. Zou, Z. Chen, H. Kang, W. Wang, R. Li, T. Li and T. Wang, Wear, 2017, 392-393, 118-125.

19 W. S. Miller and F. J. Humphreys, Scr. Metall. Mater., 1991, 25, 33-38.

20 J. B. Correia, H. A. Davies and C. M. Sellars, Acta Mater., 1997, 45, 177-190.

21 F. X. Huang, J. S. Ma, H. L. Ning, Z. T. Geng, C. Lu, S. M. Guo, X. T. Yu, T. Wang, H. Li and H. F. Lou, Scr. Mater., 2003, 48, 97-102.

22 L. Peng, H. Xie, G. Huang, Y. Li, X. Yin, X. Feng, X. Mi and Z. Yang, Mater. Sci. Eng., A, 2015, 633, 28-34.

23 T. M. Wang, M. Y. Li, H. J. Kang, W. Wang, C. L. Zou and Z. N. Chen, J. Mater. Res., 2015, 30, 248-256.

24 J. Ruzic, J. Stasic, V. Rajkovic and D. Bozic, Mater. Des., 2014, 62, 409-415.

25 Z. Y. Yan, Z. Ma, L. Liu, S. Z. Zhu and L. H. Gao, J. Eur. Ceram. Soc., 2014, 34, 2203-2209. 
26 O. Yilmaz and S. Buytoz, Compos. Sci. Technol., 2001, 61, 29 W. E. Lawrence and J. W. Wilkins, Phys. Rev. B: Condens. 2381-2392.

Matter Mater. Phys., 1973, 7, 2317-2332.

27 F. Rana and D. M. Stefanescu, Metall. Trans. A, 1989, 20, 30 G. E. Dieter, Mechanical metallurgy SI Metric Edition, 1564-1566.

McGraw-Hill Book Company (UK) Limited, UK, 1988.

28 B. Lengeler, W. Schilling and H. Wenzl, J. Low Temp. Phys., 31 Q. Zhang and D. L. Chen, Scr. Mater., $2004,51,863-867$. 1970, 2, 59-86. 